PEOPLE: International Journal of Social Sciences

ISSN 2454-5899

Chandra Shekhar Joshi, 2020

Volume 6 Issue 1, pp. 324-330

Date of Publication: $11^{\text {th }}$ April 2020

DOI- https://doi.org/10.20319/pijss.2020.61.324330

This paper can be cited as: Joshi, C. S., (2020). Emerging Subjectivity and Meaning within the Labor Process of Indian Information Technology. PEOPLE: International Journal of Social Sciences, 6(1), 324-330.

This work is licensed under the Creative Commons Attribution-Non Commercial 4.0 International License. To view a copy of this license, visit http://creativecommons.org/licenses/by-nc/4.0/ or send a letter to Creative Commons, PO Box 1866, Mountain View, CA 94042, USA.

\title{
EMERGING SUBJECTIVITY AND MEANING WITHIN THE LABOR PROCESS OF INDIAN INFORMATION TECHNOLOGY
}

\author{
Chandra Shekhar Joshi \\ National Institute of Fashion Technology, New Delhi, India \\ chandrasakher.joshi@nift.ac.in
}

\begin{abstract}
The limitless possibility of 'being', whatever one wants 'to become' in the contemporary 'liquid modern times' inherently accentuates complexities and ambiguities (Bauman 2000) in the 'conceptualization of self'. Rather than offering conduit for fulfillment and stable anchoring for personal identity (Alvesson and Willmott 2002), work in the new economy and corresponding altered employment relations, seem to impose corporate narratives of 'how one ought to be'. Resulting identities warrant for continuous identity work and thus aggravate perpetual feelings of insecurity and anxiety (Collinson 2003). In absence of traditional anchors of meaning (Sennett 1998) and corresponding unrealized quest for alternative forms of attachment and belonging (Jackall 1998), subjectivities at work are precarious at the very least. Given the context, the paper interrogates worker subjectivity within the labor process of Indian Information Technology (IT) to delineate meaningful work experiences for employees. The findings explicated from ethnographic field work indicate that despite significant contribution to the Indian economy and catapulting sizeable number of families into higher social strata, the software economy has also resulted in what has been described as 'deteriorating culture' by most of the respondents. Unsurprisingly, transactional employment relationships, eroding mutual trust and individual predisposition to self-securing orientation have been found to be prominent characteristics of Indian IT workplaces. It seems that
\end{abstract}


contradictions inherent in the individualization oriented IT labour process in a quasi-collectivistic society such as India erodes the capacity of work in providing salient identity dimensions to its employees. Interestingly, the findings from the field also indicate that work itself has no meaning but it is the instrumentality of work in achieving other life projects, particularly those associated with positive valence in the society which makes work experience as meaningful or meaningless.

\section{Keywords}

Meaningful, Information Technology, Subjectivity, Identity, Work

\section{Introduction}

We acquire the knowledge of 'what we are' and 'what we ought to be' from the interaction with others, carefully assimilating the feedback we receive and accordingly revising identity narratives. Given the prevailing norms of lifelong employment and life within physical communities, these identity narrative were relatively stable in old economy where working class was predominantly engaged in the manufacturing industry. Given the nature of work in these organizations, communication and feedback was direct and linear. In contrast new forms of employment such as 'knowledge work', requires indirect communication and obscure feedback to deal with a knowledge worker whose output is human intellect rather than tangible product. Identity construction process in such knowledge organization is thus inherently different from traditional work organizations.

Prominent amongst new employment, Information technology (IT) industry has been a significant contributor to the economic growth in India and has facilitated upward socio-economic mobility to large number of people in relatively short span of time. Indian urban landscape has as well, been metamorphosed by the growth of IT industry [Chakraborty \& Dutta 2002]. Tech parks and offices alongside malls dot cities like Gurgaon and Bangalore impacting their demographic profile and social structure. These tech parks and firms attest to two trends, one the emergence of an apparently new organizational culture and ethos far removed from the tired timelessness of an Indian PSU colony and two to the fast changing social mores and consumeristic lifestyle [Nadeem 2009a].

Both point to the emergence of the nouveau-riche and aspirational class called the 'Indian techie' who spends her or his disposable income in the malls and consumes western symbolic and material artefacts appearing to have arrived as an individual; who is an amalgamation of the wellintegrated organizational self, thought to possesses considerable individual agency and is also a 
sovereign customer. At this juncture of evolution of the Indian IT industry, this paper seeks to look backwards and now at the IT industry to explicate how it has moulded the identity of the individual self, her or his sense of agency, and significance individuals attach to impacted innovation, purpose, self-actualization and role within the larger organizational labour process?

\section{Research Methodology}

This article draws data from a larger project involving ethnographic field work. Multiple open ended informal interviews with forty two respondents were conducted from July 2017 to December 2018. Most of the fieldwork was conducted in NCR - Delhi and Bangalore while four interviews were conducted in Hyderabad. Although the companies were chosen based upon the availability of willing respondents, the diversity was purposely kept large to represent the organizations at different level of maturity, growth and size in order to capture the striking similarity and differences. The affiliating organizations of respondents include four product based (three MNC's and one Indian), seven services based (two MNC's and five Indian) and four startups (all Indian).

\section{Findings and Inferences}

Power is exercised by those in dominating positions in the class hierarchy over oppressed sections. In India, power operates through normative social practices, spoken language, identification, restrictions or facilitation of access to resources. It draws from socially embedded classification based upon economic status, cast, creed, community and even profession. Associated practices in exercising power relations constitute knowledge of 'being; for both superiors and subordinates who have effectively sustained class status across generations.

\subsection{Self as a Liberator}

Traditionally, identification was associated with familial history with limited possibility of dis-identification within the stable physical community. IT employment by virtue of holding promise of something that was possible to be acquired within short span of time is increasingly being respected and has been instrumental in upward mobility to large section of people employed in the Industry. This newly acquired economic independence provided opportunity to consistently oppressed sections to resist traditional narratives of identification and practices (such as, family or community associations, cast based work associations, generations working for the same master or 
family, ghettoed address etc). Thus for employees who have directly or vicariously (through family or community being looked down) experienced oppression, resistance to the established power structure and fortification of symbols and narratives which signified inclusion in higher social class (such as authority over number of people, residence in the posh locality, title, asset creation, international vacation) takes precedence over other pursuits. Since work is the main conduit of such liberation, organizational identity and narratives within the work become pronounced and prioritized for those coming from lower socio economic strata, oppressed communities, rural areas and those who had been relegated to lower social class in the past possibly due to constraining familial circumstances.

\subsection{Multifaceted and Multidimensional Self}

People experience their sense of identity arising out of different life experiences, individual sense of assimilation and perceptions. Socio-economic status, education, family compulsions and life stages constrain the alternatives available to a person, who navigates within the limited realm and accordingly adjusts his identity to appear coherent, stable and consistent. Accordingly, people come into the organization and have varied expectation from what the organization can do for them and what they can do for the organization. In conjunction to a particular life journey and experiences, education and culture, people may have different entanglements. Even innovation, learning or challenges may seem to be fulfilling because of their perceived instrumentality in advancing the career. Indians attach expectations to the task role. At work, each day task role throws new challenges and disproportionately high compensation provides lubrication to be driven. There is always a pre meditated task role hence most individuals have material expectations to the task role. The desired identity narratives and hence the criteria of success is defined by multiple contextual variables one is situated in. One may feel sense of fulfillment because of perceived sense of agency, the IT employment imparts in contesting established class identification, negotiating and crafting alternate socially desirable identity narratives.

The collectivistic identity earlier drew upon reservoir of continued social structure, life time jobs and intimate long lasting social relationships. The consistency of relationships as source of identity is quiet fragmented now, that continuity is broken. In absence of physical community one grew up with and large displacement from respective native communities, work affiliations remain only source of team bonding and cultivating relationships. Rising disposable income from IT employment gave sovereign consumer some sense of agency as he could travel, spent on consumption and accumulate wealth. However utilitarian and instrumental western management 
template hinders deep interconnectedness and quality relationships. Although intimate and trusting relationships develop within the workplace but are team and tenure based and sustain only until organizational goals remain common. Amid concoction of west inspired outcome based utilitarian pursuits and anchors of identities grounded in the reminiscences of the past, there is a break in the continuity of sustained and stable identities of IT worker. Consequently, monetary consideration and wealth accumulation has become the most important anchor of meaning and fulfillment for the identities decoupled from quality and meaningful relationships and limited opportunities to undertake incremental innovation and thereby supplementing organizational identity discourse with significant identity narratives beyond work (Michaelson, 2019). In absence of sustained identity narratives employees base their success and sense of fulfillment to materialistic pursuits and goals having positive social valence both within and outside work.

\subsection{Entrepreneurial Self}

People have different age cohort, cultural moorings and socio-economic grounding. Accordingly success, innovation and fulfillment have different meanings for different individuals (Rosso et al., 2010) as they craft self-serving narratives (Ashforth \& Schinoff 2016) to see value in their existence within varying and minute day to day existence. Further, the impact of western management template cannot be stereotyped as organizational culture and team culture has far significant influence on managerial and individual discourses. Also, Individuals with strong sense of self remain consistent in their preferences and opinions and may navigate their career path in such manner that there is natural alignment between corporate goals and individual pursuits. Thus some organizations and individuals, given their unique position in the matrix may be able create and pursue meaningful work with scope of innovation and continuous learning in real sense and develop collaborative work relations (Bailey et al, 2019). Influence of western management template on Indian business culture and individual mindset is not a given constant, rather a contextual variable with outcome varying upon effectiveness of leadership and location of an individual and / or organization in the evolution matrix.

\section{Conclusion}

Social integration is not possible through a model of social interaction based upon asymmetrical power relations and socialization based upon discipline intruding bodies (Kelley 1994). One of the criticism to Foucault was that people have voice to dish out their resentment. Agents cannot be conceived merely acting in compliance with established and socially accepted patterns 
which are termed as 'docile bodies' by Foucault and 'cultural dopes' by Garfinkel. Agent's own understanding of social structure and their reflexive use of cultural resources to make sense (Kelley 1994) has to be taken in account to understand variety of social interaction. Therefore their sense of identity is not static but dynamic and reflexive. The organization's job is to employ people who enter into it and utilize their skills, knowledge and abilities to add value to their products and service in order to remain competitive and profitable. It is not the task of the organization to fulfil, supply and nurture the growth of worker's identity. The organization can contribute to individual fulfillment to an extant but agency is required to be exercised by the employee to decide what it entails submerging oneself into corporate given identity discourse. However the research was only limited to gauze into employee perception, wider societal factors through which employees confer meaning could not be explored (Yeoman et al. 2019). This opens up vistas for future researches to integrate work and home dimensions of meaning and link them to wider social and cultural habitus to identify which are the areas, perceived as within the volition of the employees and which are perceived as being imposed. This in turn could pave path for researches to look into wider societal aspects which could confer meaning to even work aspects.

Sense of agency is reflexive and is constituted by the actors hence it is employee's responsibility to remain cautious while contributing to organizational goals and remain aware that corporate identity is not something which is to be internalized so deeply that organizational identity consumes other identities within work and beyond. Organizations also require to nurture complimentary sources of identification for employees both within and outside work as imposed and unitary conception of self is detrimental to organization's growth.

\section{References}

Alvesson M., \& Willmott, H. (2002). Identity regulation as organizational control: Producing the appropriate individual. Journal of Management Studies, 39(5):-619-644. https://doi.org/10.1111/1467-6486.00305

Bailey C., Lips-Wiersma, Madden A., Yeoman R., Marc Thompson M., \& Chalofskye N. (2019. The five paradoxes of meaningful work: Introduction to the special Issue 'Meaningful Work: Prospects for the 21st Century'. Journal of Management Studies. 56(3). Jhon Wiley \& Sons. https://doi.org/10.1111/joms.12422

Baumann, Z. (2000). Liquid Modernity (Cambridge: Polity UK) 
Chakraborty C. \& Dutta D. (2002) Indian Software Industry: Growth Patterns, Constraints and Government Initiatives: ASARC Working Papers

Collinson, D. L. (2003). Identities and Insecurities: Selves at Work. Organization, 10(3), 527547. https://doi.org/10.1177/13505084030103010

Edwards T. (2011) Reassessing the Employment Relationship. Springer.

Foucault, M. (2012). Discipline and punish: The birth of the prison. Vintage.

Jackall, R. (1988). Moral: The world of corporate managers. Oxford: Oxford University Press. https://doi.org/10.1007/BF01390690

Michaelson, C. (2019). A normative meaning of meaningful work. Journal of Business Ethics. Springer. https://doi.org/10.1007/s10551-019-04389-0

Rosso D., Dekas H \& Wrzesniewski A. (2010) On the Meaning of Work: A Theoretical Integration and Review. Research in Organizational Behavior. https://doi.org/10.1016/j.riob.2010.09.001

Rae G. (2010). Alienation, authenticity and the self. History of the Human Sciences. 23(4), 21-36. https://doi.org/10.1177/0952695110375763

Sennett, R. (1998). The Corrosion of character the personal consequence of work in the new capitalism. New York, NY: W.W.Norton

Sinha, J. B. (1984). A model of effective leadership styles in India. International Studies of Management \& Organization, 14(2-3), 86-98. https://doi.org/10.1080/00208825.1984.11656388

Upadhya C. (2016). Reengineering India: work Capital, Class in offshore economy. Oxford University Press. https://doi.org/10.1093/acprof:oso/9780199461486.001.0001

Upadhya C., VAsavi A.R. (2016). In an Outpost of the Global Economy: Work and Workers in India's Information Technology Industry. Routledge.

Watson, T. J. (1994). Management "flavours of the month": their role in managers' lives. International Journal of Human Resource Management, 5(4), 893-909. https://doi.org/10.1080/09585199400000071

Yeoman R. (2013). Conceptualizing Meaningful Work as a Fundamental Human need. Journal of Business Ethics. 235-251 https://doi.org/10.1007/s10551-013-1894-9

Yeoman R., Bailey C., Madden A. \& Thompason M. (2019). The oxford handbook of meaningful work. Oxford University Press.

https://doi.org/10.1093/oxfordhb/9780198788232.001.0001 